\title{
Is There Any Need for a Dike to Save Melbourne from the Rising Seas?
}

\author{
A. Parker ${ }^{1 *}$ \\ ${ }^{1}$ School of Engineering and Physical Science, James Cook University, Townsville 4811 QLD, \\ Australia.
}

\section{Author's contribution}

All work, thoughts, interpretations are done by the author.

Article Information

DOI: $10.9734 / J G E E S I / 2015 / 17463$

Editor(s):

(1) Wen-Cheng Liu, Department of Civil and Disaster Prevention Engineering, National United University, Taiwan and Taiwan Typhoon and Flood Research Institute, National United University, Taipei, Taiwan. (2) Nagendra Pratap Singh, Department of Geophysics, Banaras Hindu University, India. Reviewers:

(1) Meine Pieter van Dijk, ISS of Erasmus University Rotterdam, The Netherlands. (2) Adriano Mazzarella, University of Naples Federico II, Italy. (3) Joseph Harari, Department of Physical, Chemical and Geological Oceanography, University of Sao Paulo, Brazil. (4) Ahmed Raissouni, Department of Geology, Abdelmalek Essaâdi University, Morocco. (5) Anonymous, University of St. Thomas, USA Complete Peer review History: http://www.sciencedomain.org/review-history.php?iid=1104\&id=42\&aid=9240

Short Research Article

Received $16^{\text {th }}$ March 2015

Accepted $1^{\text {st }}$ May 2015

Published $13^{\text {th }}$ May 2015

\section{ABSTRACT}

The Australian government is still basing policy on the concept that sea level will rise by 1.1 meters along the Australian coastline by 2100. The Department of the Environment has proposed a 10 billion dollar dike to save Melbourne from the hypothetical rising sea. In reality the tide gauges of Victoria are recording average relative rates of rise of less than $1 \mathrm{~mm} / \mathrm{year}$, in perfect agreement with the National average. At this rate sea level will rise by only $8.5 \mathrm{~cm}$ by 2100 but even this estimate may be too high. The worldwide average sea level rise, based on only tide gauges of sufficient quality and length, is only about $0.25 \mathrm{~mm} / \mathrm{year}$, with zero acceleration over the last few decades. Such a rise can be dealt with by local adaption, as in the last 100 years, and there is no need for any engineering structures, let alone the proposed $10^{\prime}$ billion dollar scheme with its accompanying environmental and social problems.

Keywords: Sea level rise; climate change adaptation; Melbourne; Australia. 


\section{INTRODUCTION}

After having clarified the global empirical evidence actually available, aim of this paper is to evaluate the relative sea level rise for Melbourne, to discuss how likely is the occurrence of a sea level rise of 1 meter by 2100 claimed to motivate the 10 billion dollar sea wall project.

Measured sea-level rises have failed to match intergovernmental climate scientists' projections, yet that has not changed the government plans. The present understanding of the sea level issue by the Australian Department of the Environment [1] is the IPCC claim: "Over the last century global average sea level rose by 1.7 [1.5 to 1.9] $\mathrm{mm}$ per year, in recent years (between 1993 and 2010) this rate has increased to 3.2 [2.8 to 3.6] $\mathrm{mm}$ per year. The IPCC report finds that the rate of sea level rise over the last century is unusually high in the context of the last 2,000 years". "If emissions continue to track at the top of IPCC scenarios global average sea level could rise by nearly $1 \mathrm{~m}$ by 2100 (0.52-0.98 $\mathrm{m}$ from a 19862005 baseline). If emissions follow the lowest emissions scenario, then global average sea level could rise by between 0.28-0.6 m by 2100 (compared to a 1986-2005 baseline)".

The IPCC narrative for temperatures, sea ices, sea levels, rainfalls and whatever makes the climate is questioned by the empirical evidence. Figs. 1 to 3 presents the latest surface air and ocean 0-2000 $\mathrm{m}$ temperatures, plus the South and North Pole sea ice extensions from [2]. The warming of the surface air temperature by satellite $\mathrm{UAH}$ over the last decade is minimal. The ARGO results suffer of corrections much more than the UAH result (an initial small negative trend was corrected in a small positive trend by removing the cold temperature outliers: why not also the hot temperature outliers?) but still suggest a very modest warming. Finally, if the North Pole sea ice is shrinking the South Pole Sea ice is expanding. Over this century, the contribution by thermal expansion and mass addition to sea level rise is much less than what is predicted by the climate models and everything but significant.

For the specific of sea level rises, it has been previously commented as the lack of any acceleration in the long term tide gauges having enough information to understand a sea level rise trend are not supportive of the global warming narrative [3-35].
As an additional confirmation, Figs. 4, 5 and 6 present the tide gauges relative sea level velocities, the vertical land velocities of nearby GPS domes, and their difference, the absolute sea level velocities at the tide gauges, as computed by SONEL $[36,37]$. The starting date for the computation of the relative sea level velocities is the year 1900 . The end date is either 2011 or 1960, the longest and the shortest reasonable time window, 112 and 60 years. As the sea levels oscillate with up to a quasi-60 years' periodicity detected, windows shorter than 60 years are misleading. For those really interested in understanding if there is an accelerating pattern in the sea levels, it does not make any sense to cherry pick new tide gauges of short record length neglecting the old ones. Conversely, it is necessary to consider different time windows of the same tide gauge records, from the time the measurements become significant, i.e. 60 years of data were collected, up to the present time. Only the PSMSL [38] tide gauges with a nearby robust GPS velocity are displayed even for relative trends. The GPS time series only cover the last few years. The subsidence of a tide gauge may exceed the subsidence of an inland GPS dome cause compaction and other local phenomena. There are no surveys of the relative position of the tide gauge vs. the nearby GPS dome. This may be understood from the leveling information of the tide gauge vs. an inland datum when available. In the case of the tide gauges of Hong Kong built on reclaimed land the additional subsidence is much larger of any relative trend, as shown in [39]. The North Point tide gauge station was built on reclaimed land and the tide gauge was installed on a sea wall. Monitoring of land settlement was carried out. The height of the tide gauge benchmark was measured by precise leveling against the Hong Kong survey benchmark to an accuracy of about 4 millimeters. In view of settlement of the sea wall and revaluation of the tide gauge benchmark, the gauge was reset in 1954, 1956 and 1958. The rate of settlement was about $6 \mathrm{~mm} /$ year in the 1950s and decreased to about $2 \mathrm{~mm} /$ year in the 1980s. The nearby Quarry Bay tide gauge station had a rate of settlement of about $6 \mathrm{~mm} /$ year in the 1980s and decreased to about $2 \mathrm{~mm} / \mathrm{year}$ about 2000. From Figs. 4.a and 4.b, in the selected tide gauges the differences 1960 to 2011 are minimal. This means the sea level acceleration has been minimal. From Fig. 5, the vertical velocities of nearby inland GPS domes are more of uplift than subsidence. This not very accurate result of mostly uplift is what produces 
the mostly positive absolute sea level velocities of Figs. 6.a and 6.b. Again, what should be noticed in these images is the lack of any significant acceleration in the absolute velocities 1959 to 2011 rather than their positive values of 1959 and 2011.

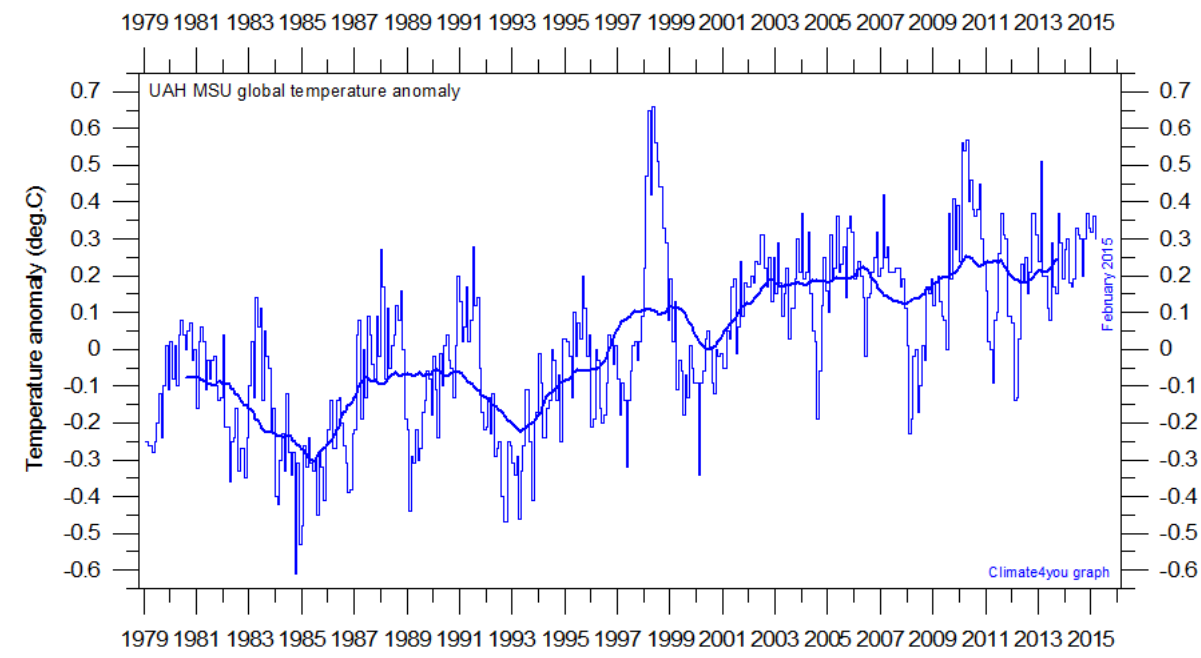

Fig. 1. Global monthly average lower troposphere temperature since 1979 according to University of Alabama at Huntsville (UAH), USA. Image is from [2]

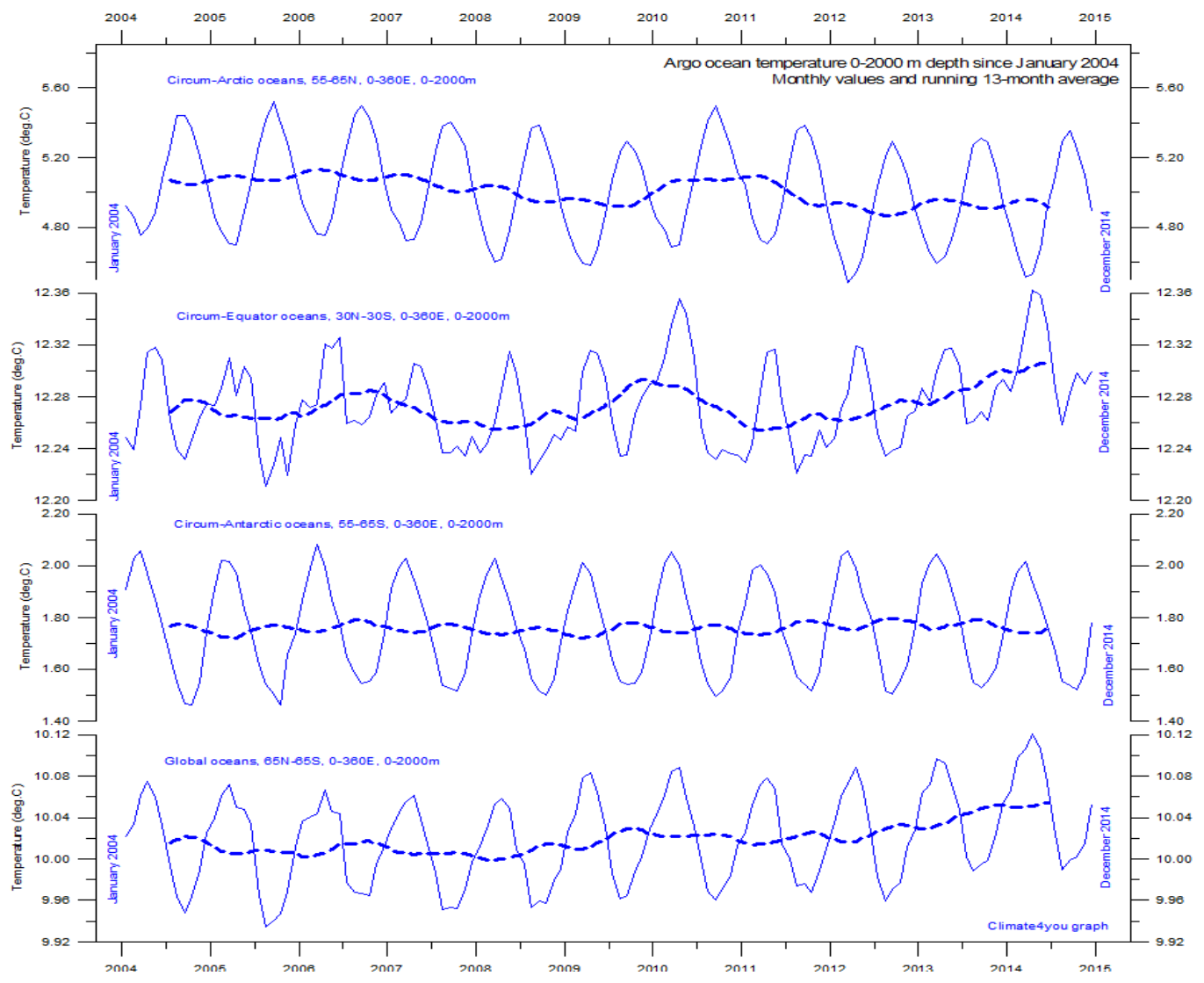

Fig. 2. Diagram showing the average $0-2000 \mathrm{~m}$ depth ocean temperatures in selected latitudinal bands by using ARGO data. The Image is from [2] 


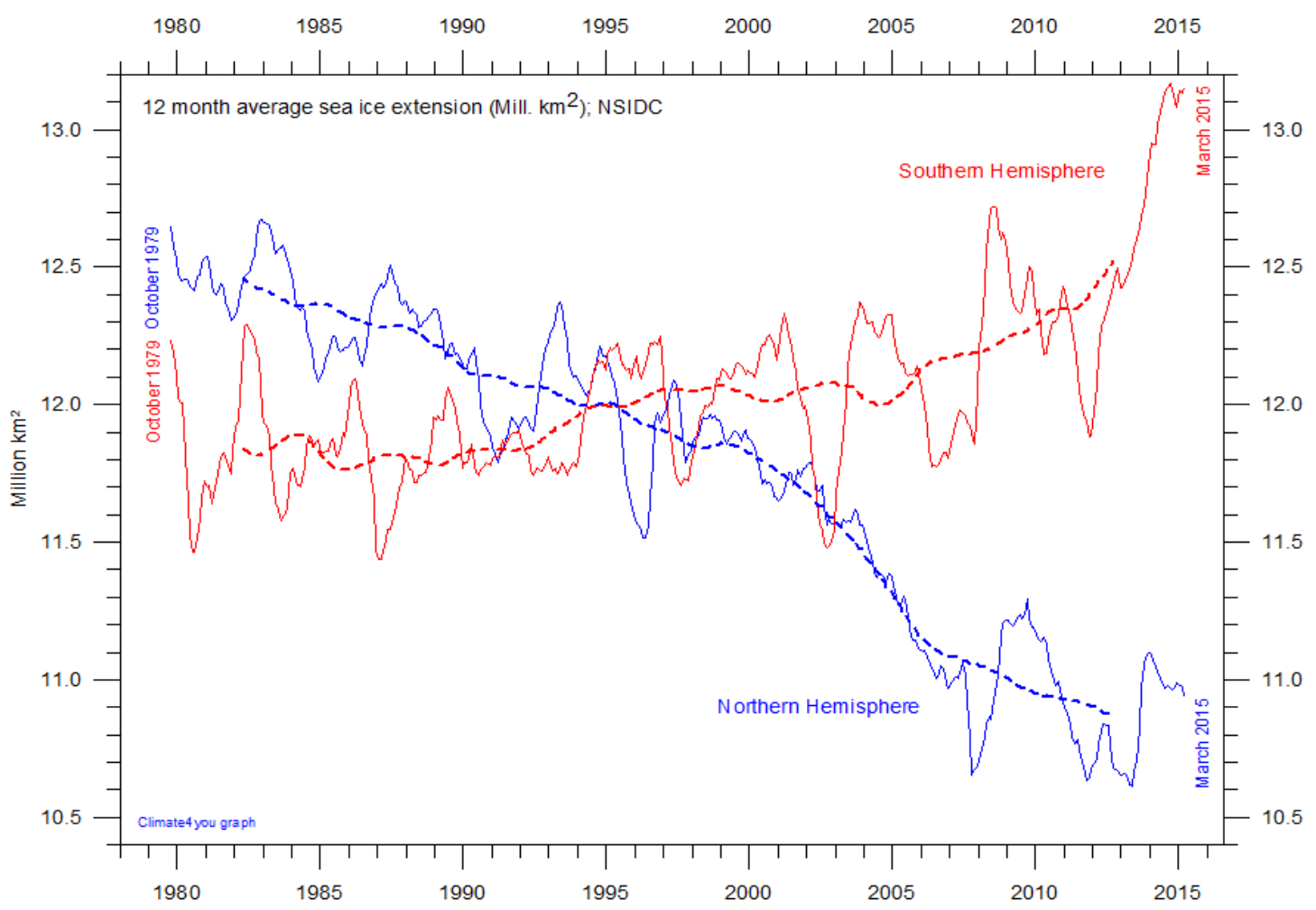

Fig. 3. 12 months running average sea ice extension in both hemispheres since 1979. The stippled lines represent a 61-month average. Data are from the National Snow and Ice Data Centre (NSIDC). Image is from [2]

For the specific of Australia and the bounding Indian and Pacific oceans, the relative rate of rise is much lower that what is claim by the intergovernmental climate scientists, linked to the subsidence at the tide gauge and free of any acceleration, as shown in [3-35]. This point will be better expanded later.

The accelerating claims from the analysis of tide gauge data may only follow the cherry picking of the information, i.e. the focus on the short time windows that magnify the relative rate of rises and the selection of the tide gauges in areas with more subsidence. Alternatively, the accelerating claims are the result of comparing past tide gauge information with present satellite altimetry that is something nobody should propose, as the scattered information from the tide gauges does not permit to infer any global mean sea level (GMSL) trend but is truly experimental, while the satellite GMSL (absolute) is mostly a computational product. As first shown in [7-9], the satellite GMSL is not an experimental product but a theoretical product. The raw satellite altimeter output is a noisy signal with a small negative rather than a largely positive trend. As this trend was not supportive of the global warming narrative, it was then arbitrarily corrected by using a glacial isostatic adjustment (GIA) model results and other arguments to tilt the original curve from an about $0 \mathrm{~mm} /$ year trend to a $+3 \mathrm{~mm} / \mathrm{year}$ trend. As discussed in [35], from 1992 to 2002, the sea level trend was indeed 0 $\mathrm{mm} / \mathrm{year}$. Then, in 2003, the same data set suddenly changed, and showed a very strong upwards trend of $2.3 \mathrm{~mm}$ per year. The reason for the correction was that otherwise there was no trend that is not exactly a good explanation to manufacture different trends.

Fig. 7 presents the map of satellite computed absolute global mean sea level (GMSL). This image is reproduced from [40]. This result shows a generalized rising trend of about $+3 \mathrm{~mm} / \mathrm{year}$ almost everywhere. As previously mentioned, this trend is only computational. The uncorrected measurement had no trend before the 2003 "correction" was arbitrarily introduced. As the uncorrected values are not available to the general public, very likely the most part of this trend is due to a "correction". 


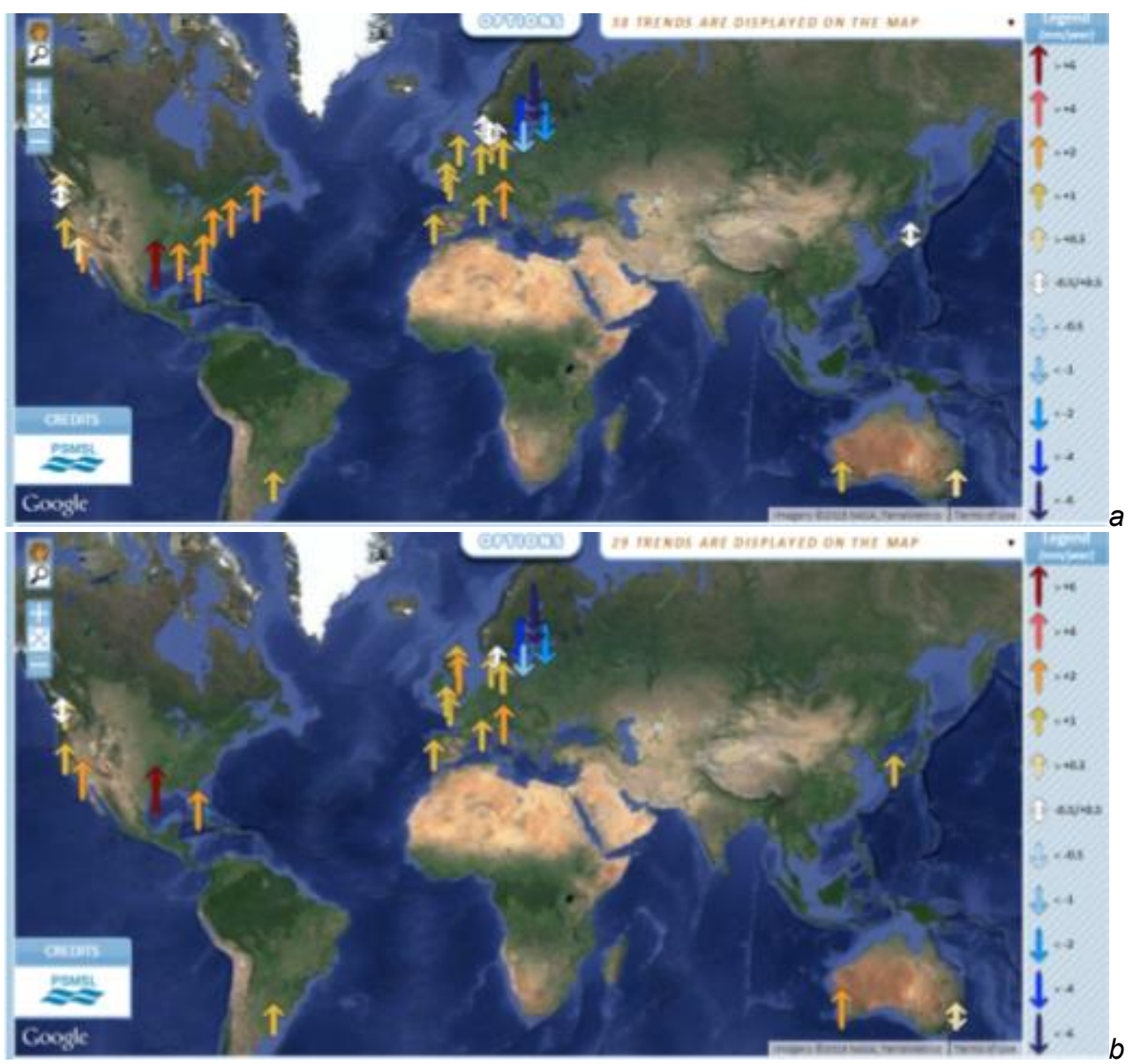

Fig. 4. Relative rate of rise of sea level from stations with data 1900 to 2011 (a) and 1900 to 1959 (b). The differences in these velocities are minimal. Images are from [37]

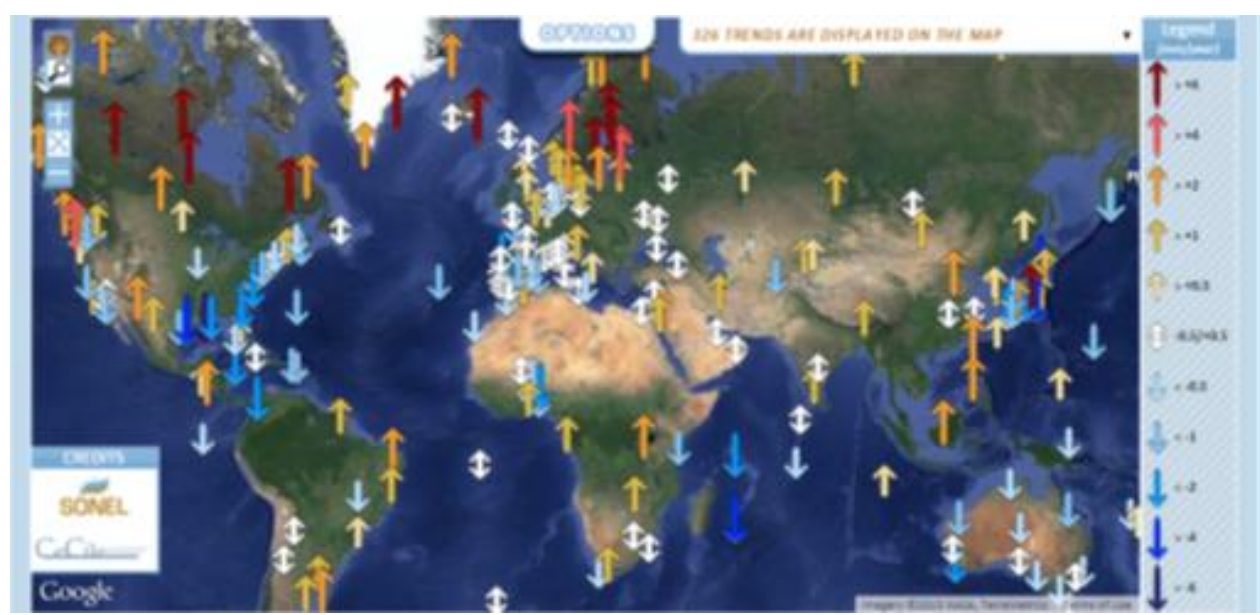

Fig. 5. Vertical land velocities of inland GPS domes close to PSMSL tide gauges. Image is from [36]. This result is not very reliable and suggests more uplift worldwide than subsidence. The subsidence at the tide gauges is certainly underrated. An overrating of the uplift translates in overrating the absolute sea level velocity 

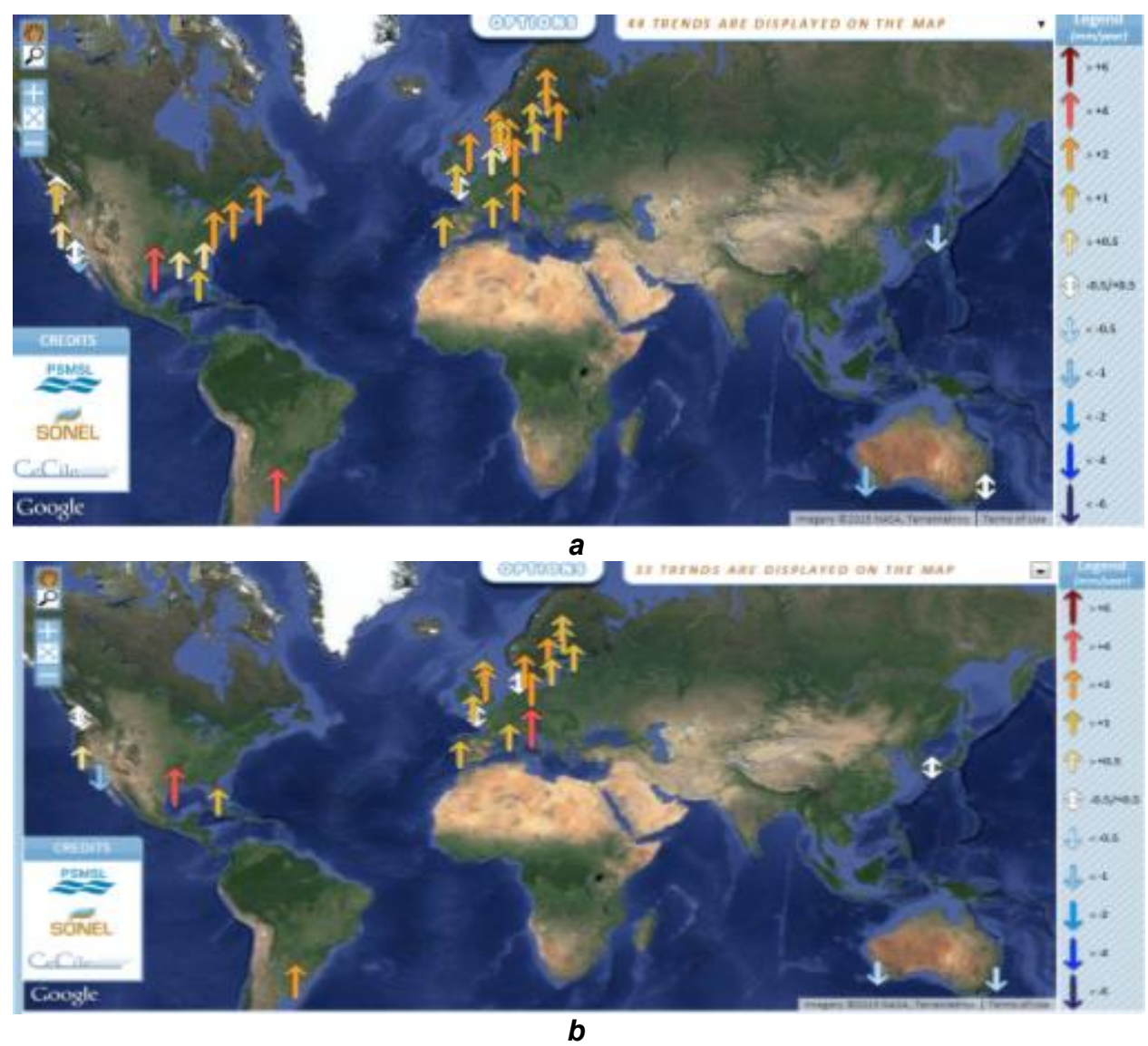

Fig. 6. Absolute rate of rise of sea level from stations with data 1900 to 2011 (a) and 1900 to 1959 (b). The absolute sea levels are rising in North Europe and North America and decreasing in Australia. Images are from [37]. This is an upper limit to the absolute rate of rise almost free of any acceleration

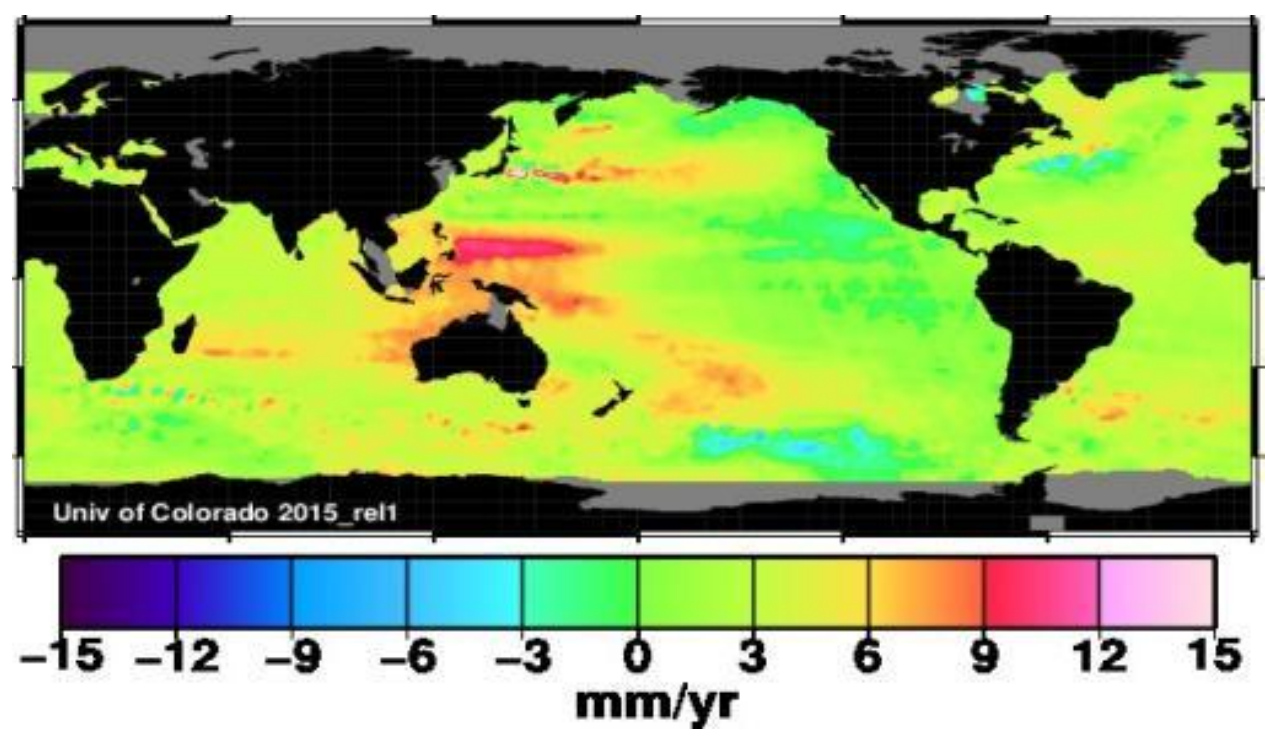

Fig. 7. Map of satellite computed absolute global mean sea level (GMSL). This image is reproduced from [40] 
As the 170 worldwide tide gauges of enough quality and length distributed along the coastline have an average relative rate of rise of +0.24 $\mathrm{mm} /$ year, this GMSL trend compares very badly with this result.

It may be argued that the tide gauge result is the sea level relative to the tide gauge that may be subject to subsidence or uplift, while the satellite result is an absolute measure. However, the above 170 tide gauges are absolutely not subject to an average uplift of $3 \mathrm{~mm} / \mathrm{year}$, and what is eventually of interest for ocean and coastal management is the relative rate of rise of the sea vs. the land. The GMSL result is therefore misleading as it defocuses from the real issue the study of sea level rise.

It may be also argued that the time window is different. As we have written many times, with less than 60 years of data the estimations of the relative sea level rates of rise at the tide gauges are meaningful. However, if this is of interest, SONEL [37] provides the absolute rates of rise at
120 tide gauges over the time window 1982 to 2011 (30 years of data is their minimum requirement). The result is shown in Fig. 8. The average of the poorly distributed 120 tide gauges has an absolute rate of rise is $+2.01 \mathrm{~mm} / \mathrm{year}$, Fig. 8.a. However, in these same tide gauges, the relative rates of rise in Fig. 8.b clearly show some areas have rising seas and some other areas have falling seas, with the tide gauges concentrated mostly in the areas of rising seas then biasing the naïve averaging mean relative rate of rise.

The lack of GMSL trend was also confirmed by the GRACE experiment. The GRACE experiment, a different satellite measuring system based on gravity rather altimetry, also returned a small negative rather than a largely positive trend. This unwanted trend was similarly adjusted through a questionable GIA model correction to a more than $2 \mathrm{~mm} /$ year trend [7-9]. Again, the tilted trend was purely speculative and based on computations and not experiments.
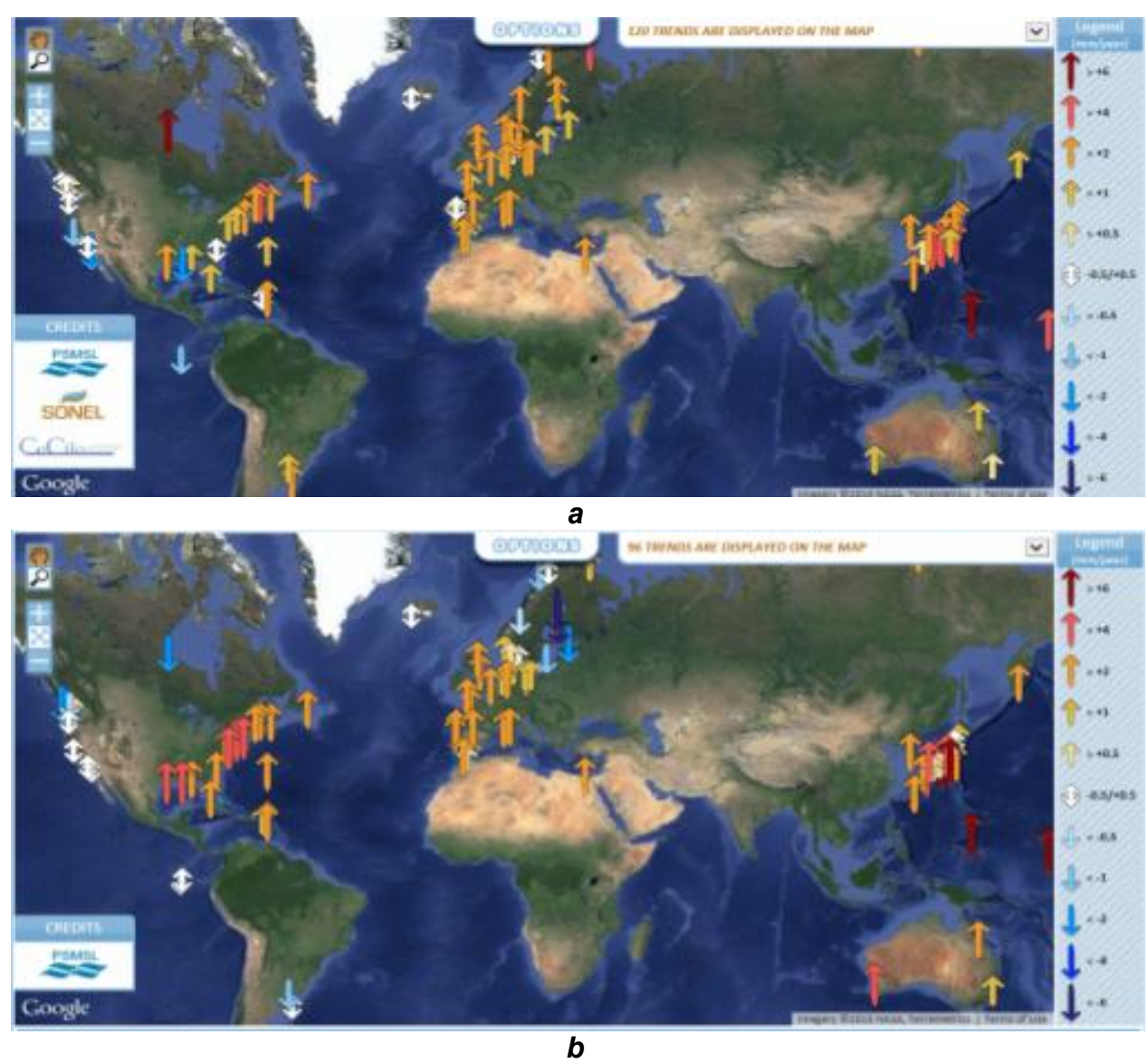

Fig. 8. Absolute (a) and relative (b) sea level rate of rise at the PSMSL-SONEL tide gauges with data 1982 to 2011. Image from [37] 


\section{THE PORT PHILIP BAY SEA WALL TO SAVE MELBOURNE}

The Department of the Environment is actually considering an option of sea level rise even larger than the IPCC predictions, following suggestions from Australian climate scientists [41-43]: "Climate change brings significant risks to the coastal zone. The Climate change risks to Australia's coasts report found that, by the turn of the century, a significant number of residential buildings may be at risk of inundation and damage from a sea level rise of 1.1 meters (high end scenario for 2100)'[42]." The Climate change risk to coastal buildings and infrastructure report identifies the exposure of coastal infrastructure to inundation and erosion from a sea level rise of 1.1 meters. The report provides data on the exposure of: commercial buildings such as retail precincts; light industrial buildings such as warehouses and manufacturing; transport systems such as road, rail and tramways." [43].

Melbourne is a low-lying coastal city, so what to do if the seas rise $1.1 \mathrm{~m}$ in what is left of this century? The proposal is of the Department of the Environment [43], a \$10 billion sea wall from Pt Nepean to Pt Lonsdale across the entrance to Port Phillip Bay is the solution considered by the department of climate change now

The dyke would need to have locks to allow water and ships to pass. The locks will be shut in case of forecasted storm surge or high tide. Because of the powerful currents and swells, constructing a dyke stretching across "The Rip" would be a difficult engineering challenge and would be very expensive, in addition to dramatically changing the environment of the area. The $\$ 10$ billion include dykes and sea-walls around the Bay, and floodgates "on every river system" feeding into it. The Department of the Environment also sees potential in harnessing the tidal power for producing green electricity, despite the repeated failure of such schemes.

The sea-level planning for 100 years ahead might seem too long-sighted but "we should actually be planning for centuries ahead in the case of major city's footprints", a concept that however does not apply in other fields such as the road and public transport system of Victoria.

The Department of the Environment has changed (temporarily) name. But as the (Coalition) government of Australia "supports the science of global warming and is making his best effort to reduce the carbon dioxide emission" and the Melbourne seawall is still mentioned in their web site and just put "on-hold" waiting more favorable conditions, an assessment of the present sea level rise for Victoria is needed.

\section{ASSESSMENTS OF SEA LEVEL RISE FOR VICTORIA}

The non-accelerating sea levels worldwide and in Australia have been the subject of many papers, as [3-6]. The worldwide average of tide gauges of sufficient quality and length in the Permanent Service on Mean Sea Level (PSMSL) data base [38] show slow rise of relative sea level of 0.24 $\mathrm{mm} /$ year without any acceleration over the last few decades [6]. The satellite based computation of the global mean sea level is similar to the many reconstruction of the past global mean sea level from tide gauge only a result manufactured by arbitrary corrections or cherry picking lacking any reliability [6].

Since the beginning of the 1990s, where many intergovernmental climate scientists sea level predictions were made to support to the global warming narrative, the sea levels have risen total 6 millimeters in a quarter of a century(average at the 100 locations satisfying minimum quality and length requirements). Even though predictions of catastrophic floods as early as 2015 have already proved to be false there is still support for the meter of sea level rise by the end of the century no matter what is actually measured.

Most of the climate scare in Australia is linked to the misuse of the sea level oscillations in a few selected locations along the Australian coastline. In the past [44], a survey of the Australian sea levels was conducted by considering all the tide gauges of Australia of length exceeding 25 years, as it was already clear that the existence of a quasi-20 years' periodic oscillation for the area made the use of short records unsuitable to compute any trend. These tide gauges were mostly managed by independent authorities as port operators, had a guarantee of transparency, and included also very long tide gauges at Sydney and Fremantle, spanning more than a century. These were good enough to show the presence of the quasi-20 years' oscillation and even a longer periodicity - the quasi-60 years' oscillation.

In Fig. 9 is a map of the distribution of the tide gauge locations with more than 25 years of recording used by the Bureau of Meteorology (BOM) to compile their latest survey conducted with a scientific approach. As the relative sea 
level trend estimates for tide gauges around Australia suggested a slow rise of less than 1 $\mathrm{mm} /$ year, the survey was censored by BOM. The trends were not supporting any alarmist message. The Australian Baseline Sea Level Monitoring Project (ABSLMP) [45] was then specifically developed to reduce attention to this good data in favor of only the few selected "high quality" tide gauges directly managed by the BOM collecting data only since the early 1990s. That a period that was very well known as a valley in the typical peak-and- valley oscillations of sea level. If we fit the points described by a sinusoidal function $y=\sin (x)$ with a line $y=a \cdot x+b$, where $x$ is the independent variable, $y$ the dependent variable, and $a$ and $b$ are constant, the focus on a time window starting in $x=3 \pi / 2$, for any other ending point that is not a multiple of $3 \pi / 2$ will show a value of a positive even if a sinusoidal function $y=\sin (x)$ has certainly not a growing pattern but only an oscillatory pattern. The classic approach to compute the sea level rise is to fit the oscillatory sea levels measured at the tide gauges with a straight line. A careful selection of the starting point can bias the assessment of relative sea level rises for a very long time. In this way the Australian Baseline Sea Level Monitoring Project may certainly continue to deliver much higher than the legitimate relative rates of rise for many more decades to come. However, the old approach of considering all the information of sufficient quality and length provides a completely different pattern.

Victoria tide gauges data are available in [46]. The summary of the data available and the relative rates of rise are presented in Table 1. The location of the tide gauges is shown in the online facility [47].

As none of the tide gauges of Victoria satisfy the minimum 60 years of data [3-5], the Sydney composite tide gauge with data obtained from [48] is also considered. Sydney has 2 tide gauges in same location, Fort Denison. SYDNEY, FORT DENISON of time span of data 1886 - 1993 and completeness 100\%, and SYDNEY, FORT DENISON 2 of time span of data 1914 - 2013 and completeness 98\%. Thanks to the 80 years of successful overlapping, the two records can be used to produce a composite record spanning 126 years.

Fig. 10 presents the monthly average mean sea levels (MSL) measured in Sydney, the history of the relative rate of rise computed in Sydney since measurement started, and finally the present relative rate of rise in Sydney with a variable start of record. In addition to the measured data, the values computed by using a linear function and multiple sinusoidal functions of parameters determined by best fitting to the measured data are also shown [3]. Clearly, the measured and fitted results are very close each other and the changes of relative rate of rise are therefore fully explained by sinusoidal oscillations and not by global warming. The long term relative rate of rise is about $0.65 \mathrm{~mm} /$ year. This value is still changing after 126 years, and before 90 years of data were collected, the relative rate of rise was very far from today's values.

Table 1. Summary of Victorian tide gauges with links to data and plots on [46]

\begin{tabular}{|c|c|c|c|c|c|c|c|}
\hline Port name & $\begin{array}{l}\text { Station } \\
\text { number }\end{array}$ & Sea level data & $\begin{array}{l}\text { SLR } \\
{[\mathrm{mm} /} \\
\text { year] }\end{array}$ & $\begin{array}{l}\text { Nominal } \\
\text { record } \\
\text { length } \\
\text { [years] }\end{array}$ & $\begin{array}{l}\text { Complet } \\
\text { eness \% }\end{array}$ & $\begin{array}{l}\text { Effective } \\
\text { record } \\
\text { length } \\
\text { [years] }\end{array}$ & $\begin{array}{l}\text { Length } \\
>25 \\
\text { years }\end{array}$ \\
\hline $\begin{array}{l}\text { Corio Bay (No1 Pt Richards } \\
\text { Channel) }\end{array}$ & $6077 \mathrm{~b}$ & Table and Plot & 11.20 & 14.92 & $97.22 \%$ & 14.50 & $\mathrm{NO}$ \\
\hline Geelong & 60770 & $\underline{\text { Table and Plot }}$ & 1.68 & 48.92 & $87.41 \%$ & 42.76 & YES \\
\hline Hovell Pile & $6072 b$ & Table and Plot & 6.13 & 22.92 & $98.55 \%$ & 22.58 & NO \\
\hline Lakes Entrance (Outer) & 60571 & $\overline{\text { Table and Plot }}$ & 10.20 & 5.92 & $95.83 \%$ & 5.67 & NO \\
\hline Lorne & $\underline{60790}$ & $\overline{\text { Table and Plot }}$ & 3.52 & 20.92 & $95.24 \%$ & 19.92 & NO \\
\hline Melbourne (Williamstown) & 60780 & Table and Plot & 2.14 & 47.92 & $99.83 \%$ & 47.83 & YES \\
\hline $\begin{array}{l}\text { Port Phillip Heads (Point } \\
\text { Lonsdale) }\end{array}$ & 60730 & $\overline{\text { Table and Plot }}$ & -0.33 & 51.92 & $97.76 \%$ & 50.75 & YES \\
\hline Port Welshpool Pier & 60590 & Table and Plot & 5.27 & 12.92 & $54.49 \%$ & 7.04 & NO \\
\hline Portland & $\underline{61410}$ & $\overline{\text { Table and Plot }}$ & 2.81 & 31.92 & $100.00 \%$ & 31.92 & YES \\
\hline Queenscliff & $6074 a$ & Table and Plot & 3.76 & 22.92 & $94.93 \%$ & 21.75 & NO \\
\hline West Channel Pile & $6072 a$ & $\overline{\text { Table and Plot }}$ & 3.71 & 22.92 & $98.55 \%$ & 22.58 & NO \\
\hline Westernport (Stony Point) & $\underline{60710}$ & Table and Plot & -1.21 & 50.92 & $68.46 \%$ & 34.86 & YES \\
\hline
\end{tabular}




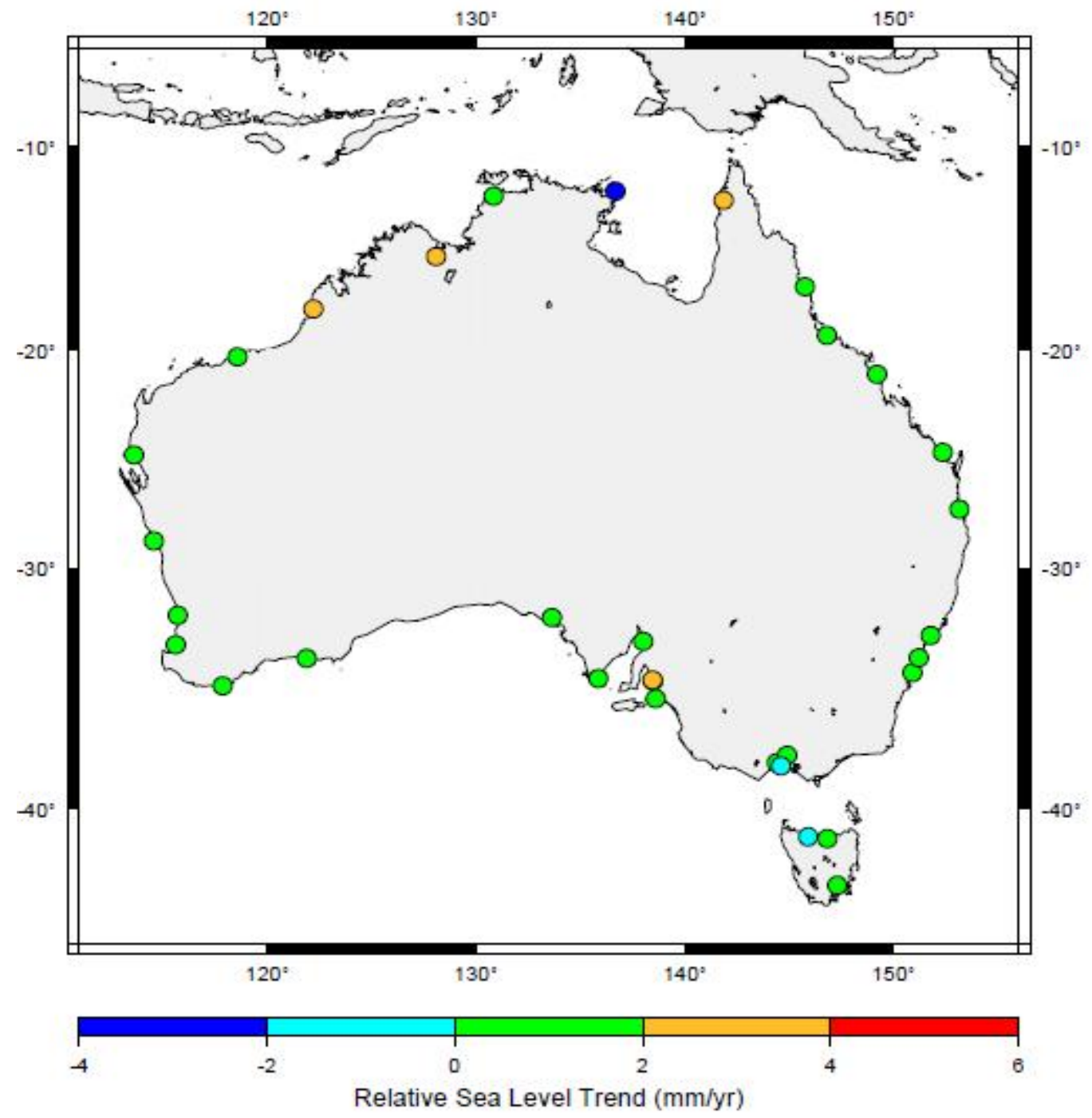

Fig. 9. Location of the tide gauges of Australia with more than 25 years of recording from the latest relative sea level rise survey reasonably conducted by BOM in 2006 [44]. Image is from

[44]. As the distribution of the relative sea level trend estimates for tide gauges around Australia was suggesting a slow rising of less than $1 \mathrm{~mm} / \mathrm{year}$ on average, the survey was censored by BOM

As we are interested in the small relative rates of rise (or fall) of the sea vs. the instrument, it must be remembered that the land is also subject to rates of rise (uplift) or fall (subsidence), that may be computed with a GPS based approach, and a coastal tide gauge may have additional subsidence vs. an inland GPS dome especially following installation. From the SONEL and JPL data bases $[49,50]$, the inland GPS dome nearby the tide gauge is subject to subsidence. According to JPL, SYDN has a subsidence of $0.426 \pm 0.327 \mathrm{~mm} /$ year slightly smaller than the present long term relative rate of rise at about $0.65 \mathrm{~mm} /$ year, while according to SONEL, SYDN has a subsidence of $-0.89 \pm 0.65 \mathrm{~mm} / \mathrm{year}$ in excess of the present long term relative rate of rise at about $0.65 \mathrm{~mm} /$ year. Considering the coastal tide gauge may be subject to additional subsidence, it seems the sea level rise in Sydney is mostly due to subsidence rather than rising seas from thermal expansion and ice melting.

Fig. 11 presents the same linear analysis of Sydney for the Point Lonsdale tide gauge, the 
tide gauge of Victoria with the longest effective record length that however still does not satisfy the minimum 60 years of length requirement. The analysis of the remaining tide gauges of Victoria of length exceeding 25 years is presented in Fig. 12.

Fig. 11.a presents the measured monthly average mean sea levels relative to the tide gauge location. The figure clearly shows that the linear trend for Point Lonsdale is of minimal fall rather than of a rise, with a rate of -0.33 $\mathrm{mm} / \mathrm{year}$, and that sea levels have oscillated up to a first peak about 1987, then down up to a valley about 1997, then up again up to the present values about the 1987 values. Other oscillations are similarly shown. Figs 11.b and 11.c then present the relative rates of rise computed over the years, as well as the present rate of rise by reducing the record length simulating the start of the measurements much later than when actually occurred. Clearly, before 35-40 years of data are collected, the relative rate of rise computed by linear fitting is often outof-scale very far from the legitimate values that are permitted only once much more than 60 years are recorded, preferably 120 years. In the last oscillation not completed yet, the relative rate of rise reduced up to 2008 , and then started to increase.

An accurate estimation is still impossible to be provided, as the record length is still insufficient, but this figure tells us what kind of overestimation (or underestimation) may be produced when focusing on the short record length starting during one of the last valley to peak oscillations. Worth of mention, as the existence of a quasi-20 years' oscillation was very well known before the global warming era [10], as a minimum 25 years of recorded data was used to compute the Australian sea level trends by considering all the available tide gauge results. It is only recently that the climate scientists only use a few selected tide gauges and over there only the most recent data incidentally since a well-known valley of the peak \& valleys oscillations - the mid-1990s - to compute the effects the evil carbon has on the Australian sea levels [45].

Victoria has 10 tide gauges in the BOM data base [47]. None satisfies the minimum 60 years requirement. The only tide gauge with more than 50 years of recording is Point Lonsdale with a relative rate of rise of $-0.33 \mathrm{~mm} / \mathrm{year}$. 5 tide gauges satisfy the minimum 25 years requirement. The average relative rate of rise in these 5 tide gauges is $+1.02 \mathrm{~mm} /$ year. Considering in Point Lonsdale the relative rate of rise is significantly larger than the actual value if less than 30-32 years of data are considered, we may state the relative rate of rise of sea levels along the Victorian coastline is less than 1 $\mathrm{mm} /$ year. Fig. 12 presents the MSL analysis in the four remaining locations satisfying the minimum 25 years of recorded data.

To understand which is the contribution of land subsidence to this result we may consider the GPS monitoring by SONEL and JPL on inland GPS domes in and close to Victoria. The results proposed by SONEL are presented in Fig. 13. SONEL has 1 location in VIC (MOBS, Melbourne, $-0.99 \pm 0.18 \mathrm{~mm} /$ year) that is subject to subsidence plus 5 locations nearby (in NSW, TAS \& SA), 4 of them with subsidence and 1 with small uplift. SONEL has an additional GPS dome close to a tide gauge, PTLD (Portland).

Even if the signal has not enough stability to compute a reliable trend, clearly the location is subject to a significant subsidence, as the GPS signal is heading down, for a significant subsidence rate above the $3 \mathrm{~mm} /$ year and larger than the relative rate of rise at the tide gauge. JPL has 3 locations near VIC (in NSW, TAS \& $\mathrm{SA}$ ) that all have subsidence.

From the above information, the sea levels are very likely rising in Victoria same the land is subsiding, with claimed contributions by thermal expansion and melting of ice are still missed here as everywhere else.

\section{DISCUSSION}

The climate scientists proposing very high sea level rise do not consider all the stations available for Australia, in particular those older and independently managed by port authorities. The oldest records of Sydney and Fremantle, the only ones measuring since the 1800 s are excluded, as well as all the other tide gauges that are not amenable to a catastrophic interpretation.

These climate scientists claim the Victorian sea levels have been rising at more than $3 \mathrm{~mm} /$ year at Lorne, Stony Point and Portland every year since 1993. Table 1 and Figs. 9-13 tell us a different story.

The ABSLMP tide gauges are not managed by independent organizations such as port authorities. They are novel SEAFRAME 
installations, theoretically providing better quality measurements but actually permitting even more

freedom for the program managers to manipulate the rate of rise of sea levels.
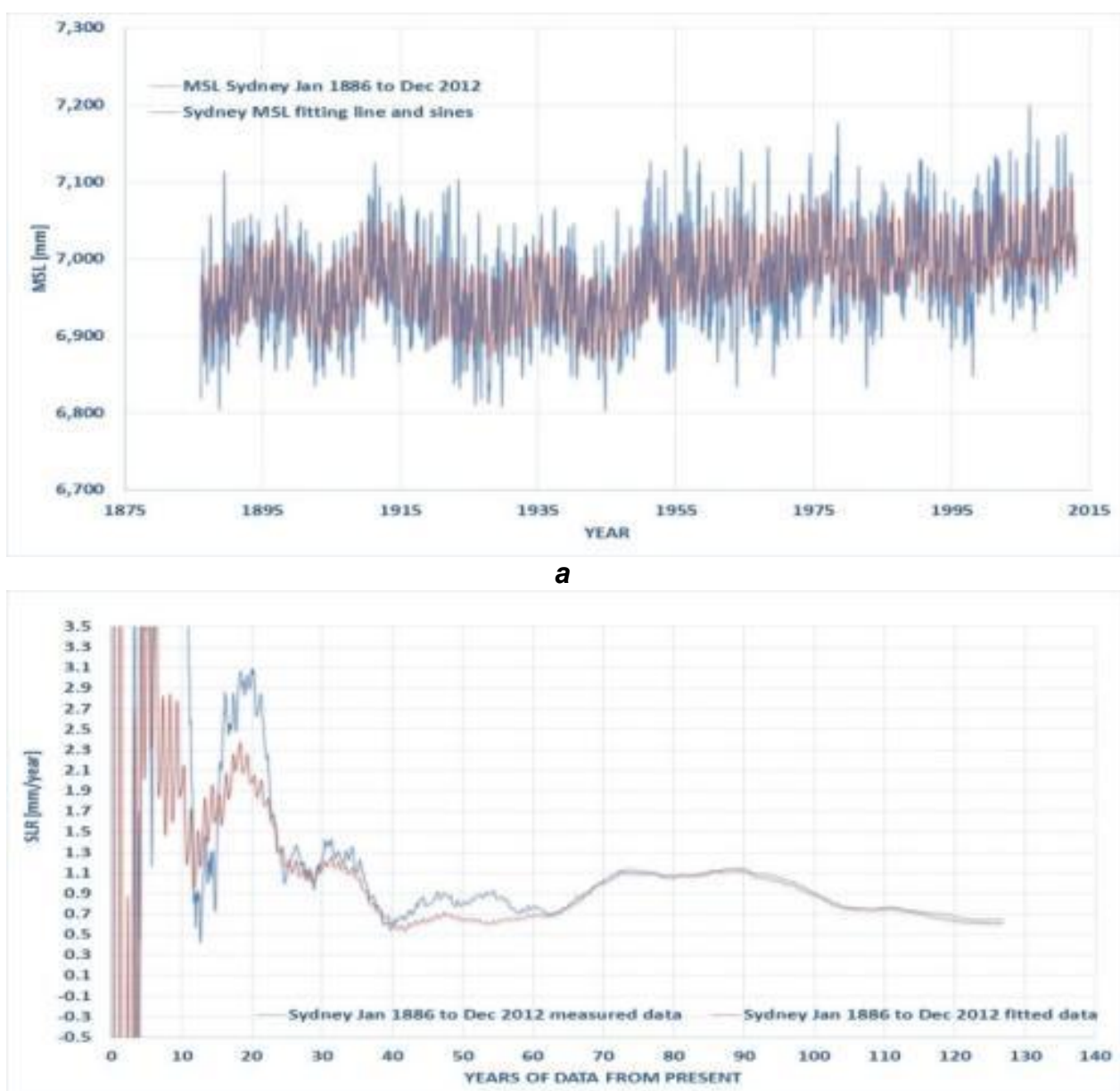

b

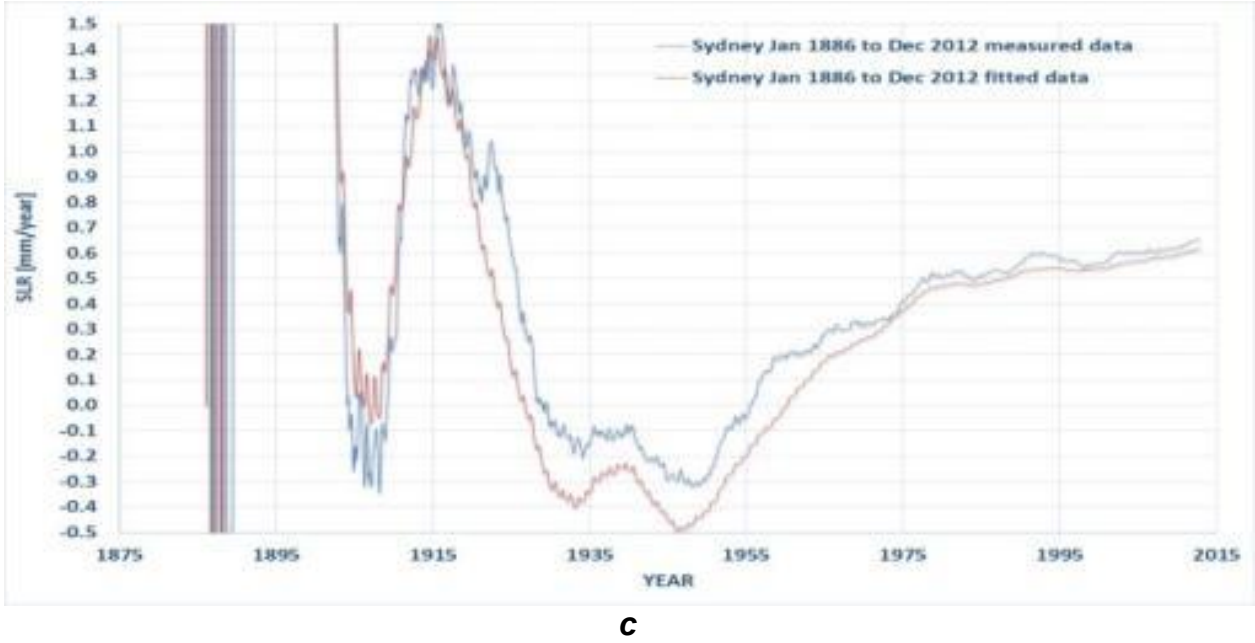

Fig. 10. MSL and sea level relative rate of rise in Sydney, NSW. a) Monthly average mean sea levels. b) Present relative rate of rise of sea levels computed with different record lengths. c) History of relative rate of rise of sea levels 


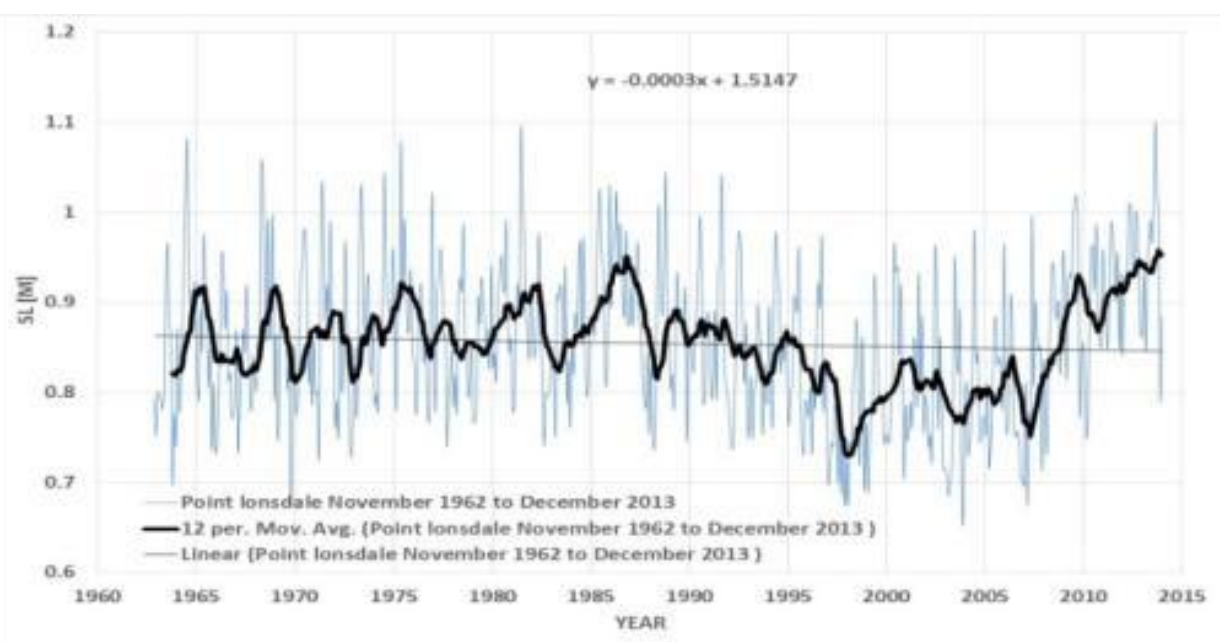

a

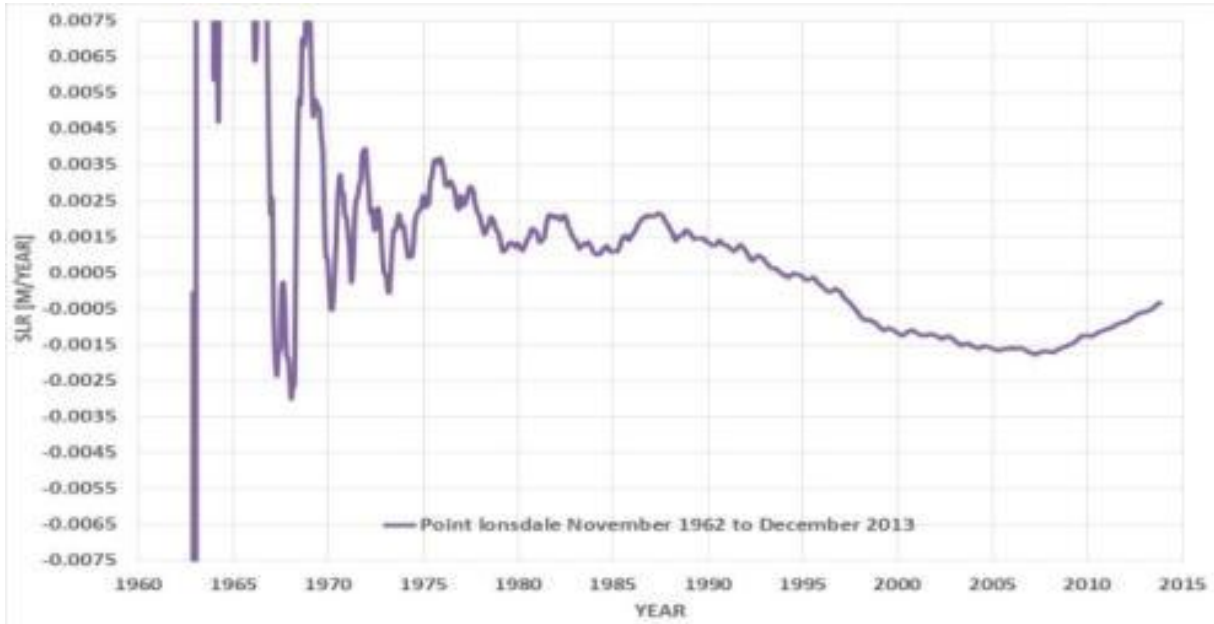

$\boldsymbol{b}$

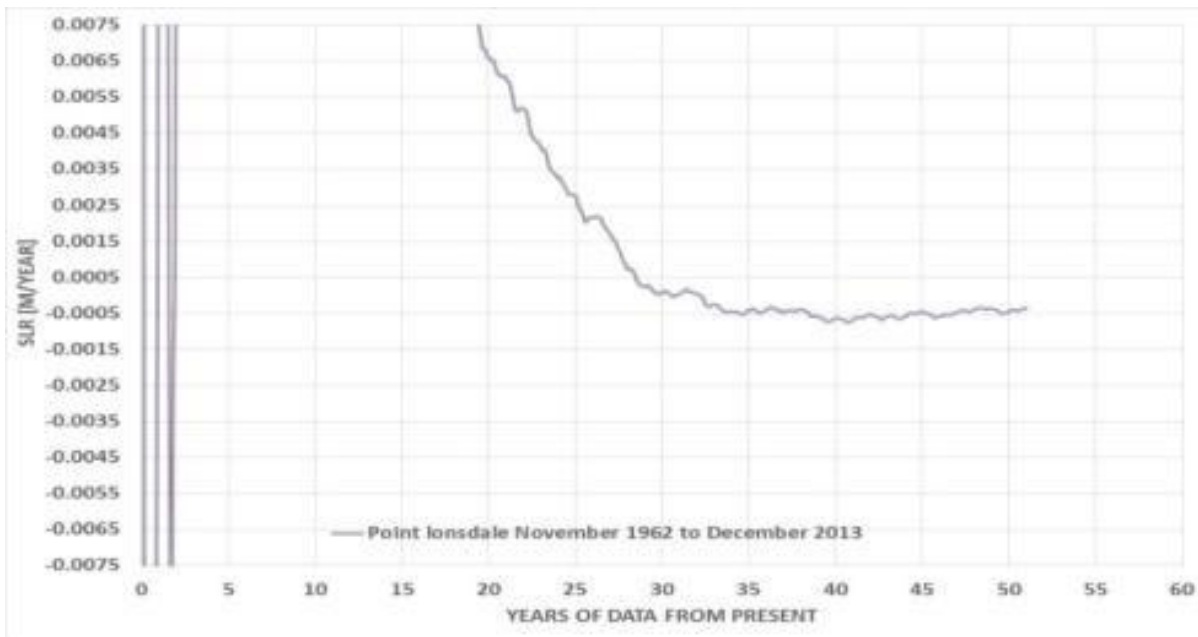

C

Fig. 11. MSL and relative rates of rise in Point Lonsdale, VIC. a) Monthly average mean sea levels. b) Present relative rate of rise of sea levels computed with different record lengths. $c$ ) History of relative rate of rise of sea levels 


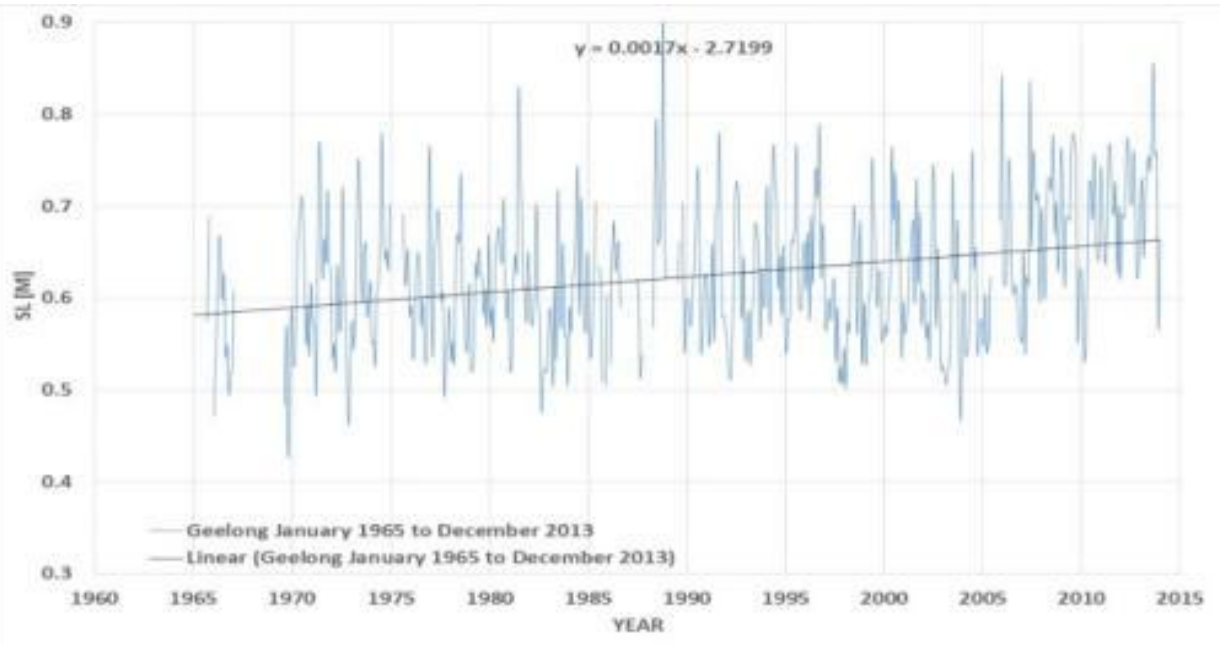

a

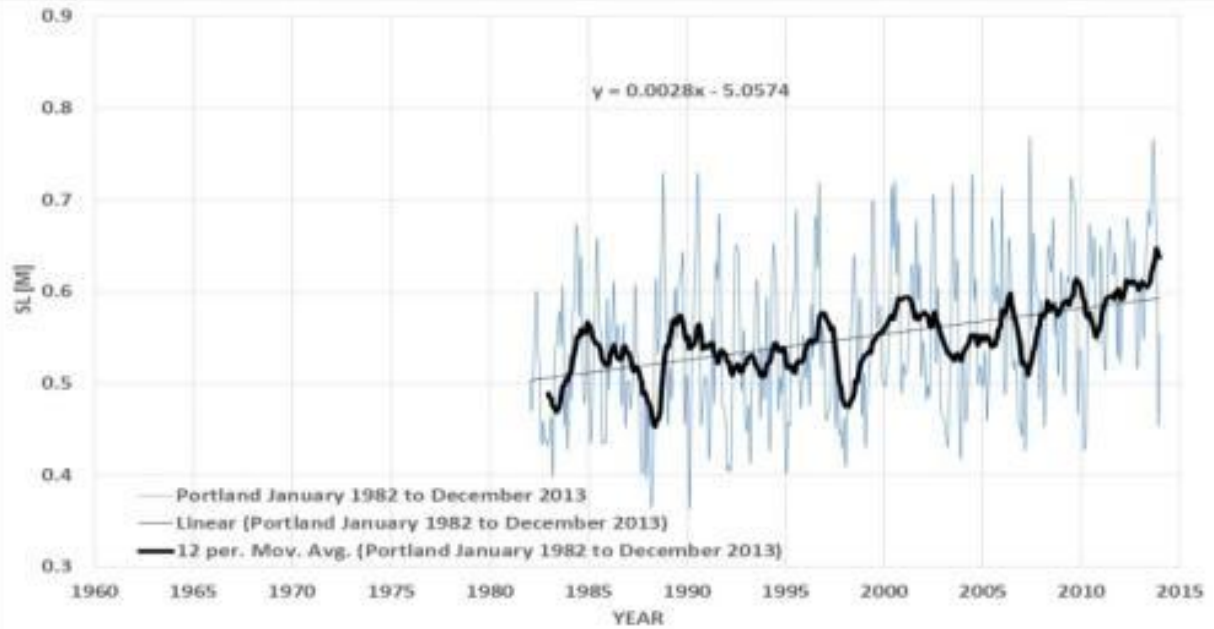

b

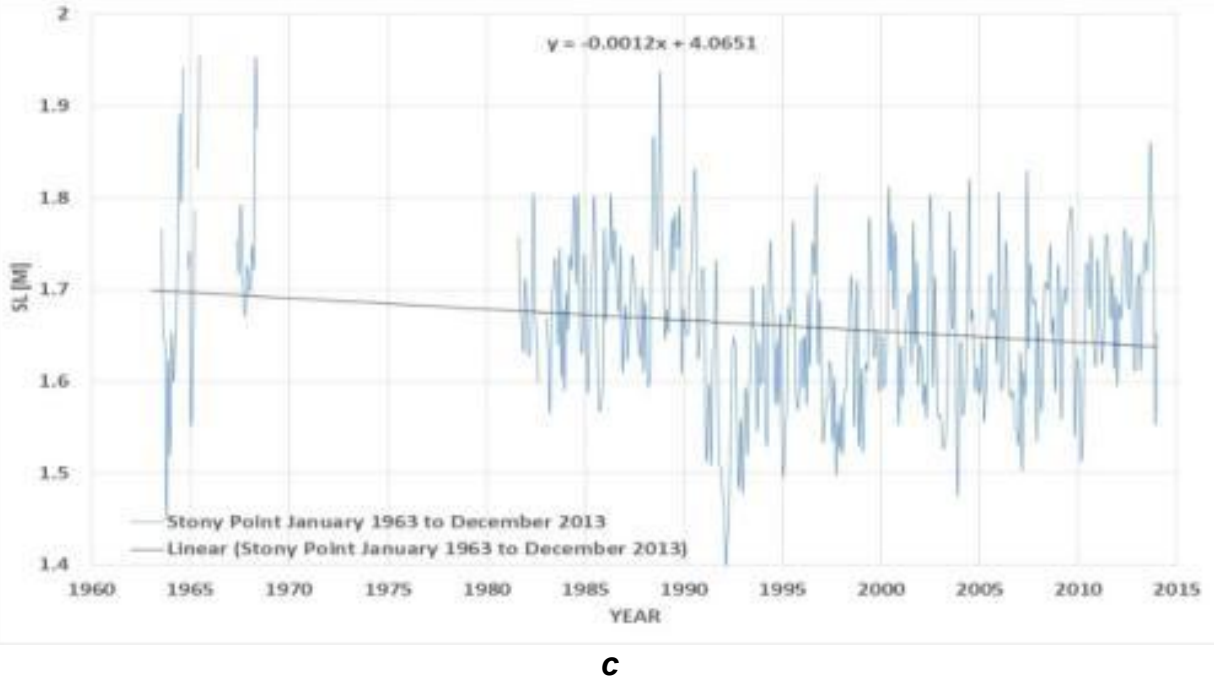

Fig. 12. continues - MSL analysis in the four remaining locations of Victoria satisfying the minimum 25 years of recorded data 


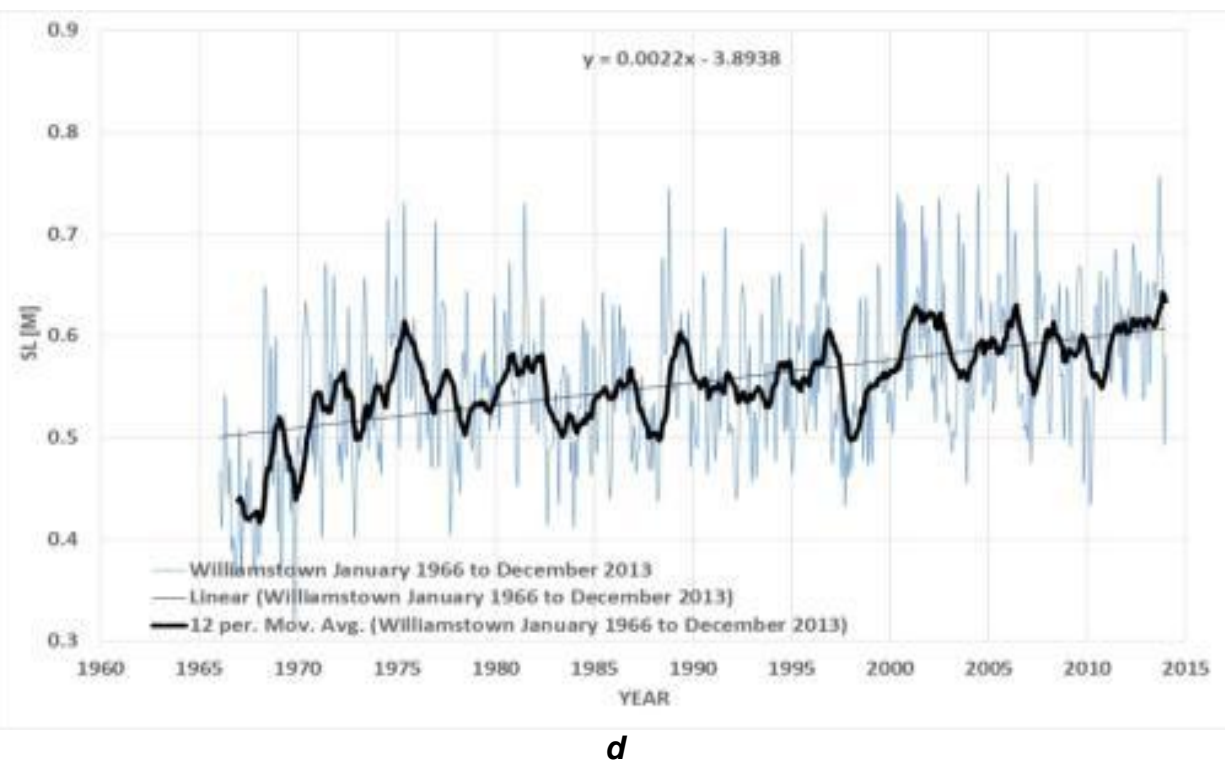

Fig. 12. Continued - MSL analysis in the four remaining locations of Victoria satisfying the minimum 25 years of recorded data

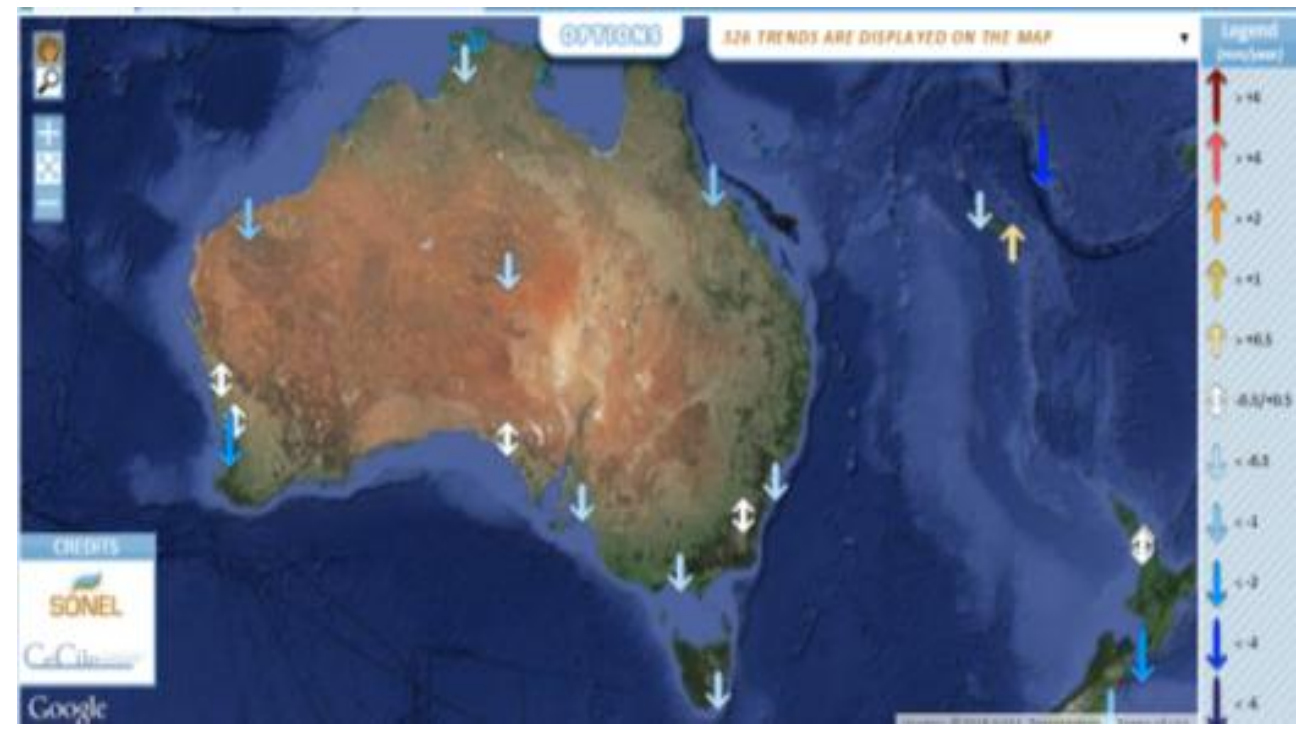

Fig. 13. Absolute vertical velocities of GPS domes in Australia computed by SONEL (image from [36])

The 3 tide gauges considered by the ABSLMP for Victoria are Portland, Lorne and Stone Point. The latest (August 2014) relative rates of rise are: Portland of relative sea level rate of rise +3.8 $\mathrm{mm} /$ year July 1991 to August 2014; Lorne of relative sea level rate of rise $+3.5 \mathrm{~mm} / \mathrm{year}$ January 1993 to August 2014; Stone Point of relative sea level rate of rise $+3.4 \mathrm{~mm} / \mathrm{year}$ January 1993 to August 2014.
These three records are very short, and start in a trough in sea level oscillation. As soon as the record length increases the influence of the short record coupled with a start in a trough in sea level is reduced.

A much better assessment of the present relative rate of rise of sea levels along the Victorian coastline and the contribution of subsidence to 
this result may be obtained by using all the tide gauge records of the NTC data base for Victoria properly accounting for the record length and completeness and the GPS domes velocities of the JPL and SONEL data bases in and around Victoria to understand how subsidence affects these results.

The SONEL and JPL results for Australia suggest the land of Australia is generally moving down. This contrasts the general understanding of Australia as a relative stable country. The SONEL and JPL result is certainly subject to large uncertainties of the order of $\pm 2 \mathrm{~mm} / \mathrm{year}$ exceeding the Australian trends [44] of less than $1 \mathrm{~mm} /$ year. However, the main reason why Australia in the Southern Hemisphere is mostly subject to subsidence while Europe, Asia and North America in the Northern Hemisphere are mostly subject to uplift are very likely the constraints given to the geodetic description of our Earth.

While it is not the right venue here to discuss the accuracy of the SONEL and JPL reconstruction, we only note here that the direct consequence of overrating the absolute sea level rises of Europe, Asia and North America with the GPS system is to underrate the absolute sea level rises of Australia.

Fig. 13 proposes the latest SONEL vertical velocities of GPS domes, with details of the Australian stations. Of the 11 stations, 10 have subsidence and only 1 has a minimal uplift. Comparison of Fig. 9 with Fig. 13 tells us the vertical land movement at the tide gauges, usually even larger than the vertical land movement of subsidence of internal GPS domes for localized phenomena as the land compaction beneath the tide gauge, may be responsible for the most part of the small sea level rise experienced in Australia.

The absolute sea level velocities proposed by SONEL [37] subtracting the vertical velocity of nearby GPS domes from the relative velocity measured at the nearby tide gauges that are also included in the PSMSL data bases show the absolute sea level rise around Australia seems indeed very small, and actually negative. With a 60 years' time window 1952 to 2011 for the computation of the relative sea level rise component, the only 3 tide gauges to be considered are Fremantle with a negative absolute sea level velocity of $-1.47 \pm 0.35$ $\mathrm{mm} /$ year, Sydney with negative absolute sea level velocity of $-0.15 \pm 0.34 \mathrm{~mm} /$ year, and Townsville with a small positive absolute sea level velocity of $0.15 \pm 0.38 \mathrm{~mm} /$ year.

According to SONEL, the subsidence for the area of Victoria and for Australia is $1 \mathrm{~mm} / \mathrm{year}$, about the same average relative rate of rise measured at the tide gauges when properly assessed by using enough data. A 1 metre sea level rise is therefore plausible in 1,000 years. The relative sea level is slow rising (or slow falling) not that far from the subsidence (or uplift) of the different areas (in the North of Europe or Alaska the sea levels are falling because of the Glacial Isostatic Rebound), with accelerations negligibly positive or negative. Without any sign the sea level rise would pose any treat to Melbourne, there are certainly many other more urgent works as to make asbestos free our schools or improve the collapsing road and railway system rather than building at huge economic costs a not needed dike also dramatically impacting the environment.

\section{CONCLUSION}

On the basis of the data presented here the average rise of sea level along the Victorian coastline is very likely less than $1 \mathrm{~mm}$ /year. The worldwide shows no acceleration in the rate of rise, so there is probably no acceleration in Victoria. This rise in sea level gives no cause for concern. The likelihood of a 1.1 meter sea level rise by 2100 is extremely improbable, in Melbourne and along the Australian coastline in general. The department of the environment should not seek advice from the same discredited climate agencies that advised the previous Labor government and conclude there is in impending threat of huge sea level rise. Their proposed 10 billion dollar dike is not needed to save Melbourne from the rising seas.

The paper shows that there is not an urgent need to build a very expensive dam to protect Melbourne by sea level increase of more than one meter by 2100 as forecasted by the IPCC. The paper criticizes the IPCC and the local sea level monitoring projects and shows that sea level as measured by other longer and not investigated tide gauges is much less than 1 $\mathrm{mm} /$ year. So the proposed 10 billion dollar dike is not needed to save Melbourne from the rising seas. The paper shows that the sea levels oscillate with up to a quasi-60 years' periodicity 
detected, for which windows shorter than 60 years are misleading. On the other hand, the average of tide gauges of sufficient quality and length in the Permanent Service on Mean Sea Level (PSMSL) data base show a slow rise of relative sea level of $0.24 \mathrm{~mm} /$ year without any acceleration over the last few decades. The paper shows that the lack of trend in MSL was also confirmed by the GRACE experiment that is a satellite measuring system based on gravity rather altimetry. The Australian Department of the Environment before basing policy on the concept that sea level will rise by 1.1 meters along the Australian coastline by 2100 should take into account the views expressed in this paper.

\section{COMPETING INTERESTS}

The author has no financial and personal relationships with other people or organizations that could inappropriately influence (bias) the work.

\section{REFERENCES}

1. Available:www.environment.gov.au/climate -change/climate-science/climate-changefuture/sea-level

2. Available:www.climate4you.com/

3. Parker A, Saad Saleem M, Lawson M. Sea-level trend analysis for coastal management. Ocean \& Coastal Management. 2013;73:63-81.

DOI: 10.1016/j.ocecoaman.2012.12.005.

4. Parker A. Minimum 60 years of recording are needed to compute the sea level rate of rise in the Western South Pacific. Nonlinear Engineering; 2014.

DOI:10.1515/nleng-2013-0011.

5. Parker A. Present contributions to sea level rise by thermal expansion and ice melting and implication on coastal management. Ocean and Coastal Management. 2014;98:202-211.

DOI:10.1016/j.ocecoaman.2014.05.026

6. Parker A. Persisting problems affecting the reliability of the satellite altimeter based Global Mean Sea Level computation, Pattern Recognition in Physics. 2014;02(02):65-74.

Available:www.pattern-recognition-inphysics.com/pub/prp-2-65-2014.pdf
7. Mörner N. The great sea-level HUMBUG. There Is No Alarming Sea Level Rise!, 21st Century Science \& Technology. 2011; Winter 2010/2011:12-22.

8. Mörner N. Sea level changes past records and future expectations. Energy \& Environment. 2013;24(3 \& 4).

9. Mörner N. Sea level changes and crustal movements with special aspects on the Mediterranean Z, Geomorph NF. 2005; 137: 91-102.

10. Boretti A, Watson T. The inconvenient truth: Ocean Levels are not accelerating in Australia or over the world, Energy \& Environment. 2012;23(5):801-817.

11. Boretti $A$. Is there any support in the long term tide gauge data to the claims that parts of Sydney will be swamped by rising sea levels? Coastal Engineering. 2012;64: 161-167.

12. Boretti A. Discussion of Cooper JAG. Lemckert C. Extreme sea level rise and adaptation options for coastal resort cities: A qualitative assessment from the Gold Coast, Australia, Ocean \& Coastal Management, In Press, Accepted Manuscript, Available online 18 April 2012, Ocean and Coastal Management. 2012; 78:132-135.

13. Parker A. Comment on Low-frequency sea level variation and its correlation with climate events in the Pacific. Chinese Science Bulletin. 2013;58(14):1708-1713.

14. Mörner NA, Parker A. Present-to-future sea level changes: The Australian case, Environmental Sciences: An Indian Journal. 2013;8(2).

Available:tsijournals.com/esaij/Vol8Iss2/AB S01.htm

15. Parker A. Natural oscillations and trends in long-term tide gauge records from the Pacific, Pattern Recogn. Phys. 2013;1:113.

Available:www.pattern-recognphys.net/1/1/2013/ DOI:10.5194/prp-1-1-2013.

16. Parker A, Watson T. Discussion of "towards a global regionally varying allowance for sea-level rise" by Hunter JR, Church JA, White NJ, Zhang X. [Ocean Engineering. 2013;71(1):17-27. Ocean Engineering. 2013;72:470-472.

17. Parker A. Reply to Comment on Sea-Level Trend Analysis for Coastal Management 
by Parker A, Saad Saleem M, Lawson M. Ocean \& Coastal Management. 2013; 87:116-118.

18. Parker A. Confirming the lack of any sea level acceleration around the Australian coastline, Nonlinear Engineering. 2014; 3(2):99-105.

19. Parker A. Assessment of 20th century sea level rise in New Zealand including measurement inaccuracy, Environmental Science: An Indian Journal. 2014;10(2). Available:www.publicationhosting.org/toc/a rticle.php?id=3007

20. Parker A, Ollier CD. Cherries, apples and sea levels: Discussion of Neil J. White et al., Australian sea levels -Trends, regional variability and influencing factors, EarthScience Reviews. Environmental Science: An Indian Journal. 2015;136(2014):155174 10(6).

Available:www.publicationhosting.org/toc/a rticle.php?id=5972

21. Parker A, Ollier CD. Sea level rise for India since the start of tide gauge records, Arabian Journal of Geosciences; 2015. (Published online 09 Dec 2014). DOI:10.1007/s12517-014-1739-6.

22. Douglas BC. Global sea level acceleration, J. Geophys. Res. 1992;97(C8):1269912706.

23. Douglas B, Peltier WR. The Puzzle of Global Sea-Level Rise. Physics Today. 2002;55(3):35-40.

24. Jevrejeva $S$, et al. Nonlinear trends and multiyear cycles in sea level records. J. Geophysical Research. 2006;111:C09012.

25. Holgate SJ. On the decadal rates of sea level change during the twentieth century. Geophysical Research Letters. 2007;34: L01602.

26. Wunsch R, Ponte R, Heimbach P. Decadal trends in sea level patterns: 1993-2004. Journal of Climatology. 2007;5889-5911.

27. Woodworth $P$, et al. Evidence for the accelerations of sea level on multi-decade and century timescales. International Journal of Climatology. 2009;29(6):777789.

28. Wenzel M, Schröter J. Reconstruction of regional mean sea level anomalies from tide gauges using neural networks. Journal of Geophysical Research - Oceans. 2010; 115:C08013.
29. Mörner NA. Sea level changes in Bangladesh new observational facts. Energy and Environment. 2010;21(3):235249.

30. Mörner NA. Some problems in the reconstruction of mean sea level and its changes with time. Quaternary International. 2010;221(1-2):3-8.

31. Houston JR, Dean RG. Sea-Level acceleration based on U.S. Tide gauges and extensions of previous global-gauge analyses. Journal of Coastal Research. 2011;27:409-417.

32. Watson PJ. Is there evidence yet of acceleration in mean sea level rise around mainland Australia? Journal of Coastal Research. 2011;27:368-377.

33. Schmith T, Johansen S, Thejll P. Statistical Analysis of global surface temperature and sea level using cointegration methods. J. Climate. 2012;25:7822-7833.

34. Scafetta N. Discussion on common errors in analyzing sea level accelerations, solar trends and global warming. Pattern Recognition in Physics. 2013;1:37-57.

35. Available:hockeyschtick.blogspot.com.au/2 010/02/sea-level-expert-sea-is-notrising.html

36. Available:www.sonel.org/-Vertical-landmovement-estimate-.html?lang=en

37. Available:www.sonel.org/-Sea-level-trendshtml?lang=en

38. Available:www.psmsl.org

39. Available:www.weather.gov.hk/publica/repr int/r556.pdf

40. Available:http://sealevel.colorado.edu/cont ent/map-sea-level-trends

41. Available:www.environment.gov.au/climate -change/adaptation/publications/climatechange-risks-australias-coasts

42. Available:www.environment.gov.au/system /files/resources/fa553e97-2ead-47bb-ac80c12adffea944/files/cc-risks-full-report.pdf

43. Available:www.environment.gov.au/climate -change/adaptation/publications/climatechange-risks-coastal-buildings

44. Available:www.environment.gov.au/system /files/pages/bc2321cc-fc25-4a09-808bbe6cbe755808/files/co03austmeansealeve Isurvey2003.pdf

45. Available:www.bom.gov.au/oceanographyl projects/abslmp/abslmp.shtml 
46. Available:www.bom.gov.au/oceanographyl projects/ntc/monthlyl

47. Available:www.bom.gov.au/australia/tides/ \#!/vic

48. Available:www.psmsl.org/data/
49. Available:www. sonel.org/spip.php?page $=\mathrm{g}$ ps\&idStation $=X X X(X X X$ is the three digits station number)

50. Available:sideshow.jpl.nasa.gov/post/links/ $\underline{X X X X . h t m l}(X X X X$ is the four digit station name)

(c) 2015 Parker; This is an Open Access article distributed under the terms of the Creative Commons Attribution License (http://creativecommons.org/licenses/by/4.0), which permits unrestricted use, distribution, and reproduction in any medium, provided the original work is properly cited.

Peer-review history:

The peer review history for this paper can be accessed here:

http://www.sciencedomain.org/review-history.php?iid=1104\&id=42\&aid=9240 